\title{
Corrigendum: Human immunodeficiency virus 1 Nef suppresses CD40- dependent immunoglobulin class switching in bystander B cells
}

Xugang Qiao, Bing He, April Chiu, Daniel M Knowles, Amy Chadburn \& Andrea Cerutti

Nat. Immunol. 7, 302-310 (2006); published online 22 January 2006; corrected after print 29 July 2016

In the version of the article originally published, in the top immunoblot (loading control) in Figure 5f, the right half was incorrectly a mirrorimage duplication of the left half. The correct immunoblot from a replicate experiment is now presented (along with the corresponding bottom immunoblot). The error has been corrected in the HTML and PDF versions of the article.

\section{Corrigendum: Gut microbiome-derived metabolites modulate intestinal epithelial cell damage and mitigate graft-versus-host disease}

\author{
Nathan D Mathewson, Robert Jenq, Anna V Mathew, Mark Koenigsknecht, Alan Hanash, Tomomi Toubai, Katherine Oravecz-Wilson, \\ Shin-Rong Wu, Yaping Sun, Corinne Rossi, Hideaki Fujiwara, Jaeman Byun, Yusuke Shono, Caroline Lindemans, Marco Calafiore, \\ Thomas C Schmidt, Kenya Honda, Vincent B Young, Subramaniam Pennathur, Marcel van den Brink \& Pavan Reddy \\ Nat. Immunol. 17, 505-513 (2016); published online 21 March 2016; corrected after print 26 August 2016
}

In the version of this article initially published, the middle initial (C) for the sixteenth author was incorrect. The correct author name should be Thomas M. Schmidt (and the corresponding initials in the Author Contributions section should be T.M.S.). The error has been corrected in the HTML and PDF versions of the article.

\section{Erratum: CD69 controls the uptake of L-tryptophan through LAT1-CD98 and AhR-dependent secretion of IL-22 in psoriasis}

\author{
Danay Cibrian, María Laura Saiz, Hortensia de la Fuente, Raquel Sánchez-Díaz, Olga Moreno-Gonzalo, Inmaculada Jorge, \\ Alessia Ferrarini, Jesús Vázquez, Carmen Punzón, Manuel Fresno, Miguel Vicente-Manzanares, Esteban Daudén, \\ Pedro M Fernández-Salguero, Pilar Martín \& Francisco Sánchez-Madrid \\ Nat. Immunol.; doi:10.1038/ni.3504; corrected online 11 July 2016
}

In the version of this article initially published online, the identification of dermal and epidermal $\gamma \delta \mathrm{T}$ cells in the legend for Figure $3 \mathrm{f} \mathrm{was} \mathrm{reversed;}$ a label was missing above the far left column of Figure 4c; and the red and blue lines were switched in the keys for the far right plots in Figure 6i. The legend for Figure $3 \mathrm{f}$ should read "...identified by high expression (top right; epidermal) or low expression (bottom right; dermal) of the $\gamma \delta$ TCR." The far left column in Figure 4c should include the label "CD69-KO" above. The correct keys for Figure 6i are as follows: blue line, FIZC $\left(37^{\circ} \mathrm{C}\right)$, and red line, FICZ $+\mathrm{BCH}\left(37^{\circ} \mathrm{C}\right)$; and blue line, $\mathrm{CD} 69-\mathrm{KO}\left(37^{\circ} \mathrm{C}\right)$, and red line, $\mathrm{WT}\left(37^{\circ} \mathrm{C}\right)$. These errors have been corrected for the print, PDF and HTML versions of this article.

\section{Erratum: Activin A programs the differentiation of human $\mathrm{T}_{\mathrm{FH}}$ cells}

Michela Locci, Jennifer E Wu, Fortuna Arumemi, Zbigniew Mikulski, Carol Dahlberg, Andrew T Miller \& Shane Crotty Nat. Immunol. 17, 976-984 (2016); published online 4 July 2016; corrected after print 20 July 2016

In the version of this article initially published, some of the statistical comparisons in Figures $3 \mathrm{f}, 3 \mathrm{l}, 3 \mathrm{~m}, 4 \mathrm{a}, 4 \mathrm{~d}, 4 \mathrm{e}, 5 \mathrm{~g}$, 6b, 6c and 7d were presented incorrectly in the plots. Also, 'in vitro' was not fully in italics in the abstract, and the author list for reference 36 was incorrect. The errors have been corrected in the HTML and PDF versions of the article. 